\title{
Aggression and seclusion on acute psychiatric wards: effect of short-term risk assessment
}

\author{
R. van de Sande, H. L. I. Nijman, E. O. Noorthoorn, A. I. Wierdsma, E. Hellendoorn, \\ C. van der Staak and C. L. Mulder
}

\section{Background}

Short-term structured risk assessment is presumed to reduce incidents of aggression and seclusion on acute psychiatric wards. Controlled studies of this approach are scarce.

\begin{abstract}
Aims
To evaluate the effect of risk assessment on the number of aggression incidents and time in seclusion for patients admitted to acute psychiatric wards.

\section{Method}

A cluster randomised controlled trial was conducted in four wards over a 40-week period ( $n=597$ patients). Structured risk assessment scales were used on two experimental wards, and the numbers of incidents of aggression and seclusion were compared with two control wards where assessment was based purely on clinical judgement.
\end{abstract}

\section{Results}

The numbers of aggressive incidents (relative risk reduction $-68 \%, P<0.001)$ and of patients engaging in aggression (relative risk reduction RRR $=-50 \%, P<0.05$ ) and the time spent in seclusion (RRR $=-45 \%, P<0.05$ ) were significantly lower in the experimental wards than in the control wards. Neither the number of seclusions nor the number of patients exposed to seclusion decreased.

\section{Conclusions}

Routine application of structured risk assessment measures might help reduce incidents of aggression and use of restraint and seclusion in psychiatric wards.

\section{Declaration of interest}

None.
Internationally, a wide variety of coercive interventions to manage the risk of violence and self-harm can be identified. ${ }^{1,2}$ The therapeutic effects of seclusion, if any, have been questioned in a number of publications. ${ }^{3-6}$ Several qualitative studies suggest that seclusion evokes extremely negative and traumatic experiences for many patients. ${ }^{7-9}$ Despite the negative impact seclusion may have on patients, a Cochrane review covering 2155 citations found no randomised controlled study investigating the effects of interventions aiming at reducing seclusion. ${ }^{10}$ Likewise, more recent reviews by Gaskin et al and Bowers et al could not identify welldesigned studies in this domain since 2000. ${ }^{11,12}$ Nevertheless, several authors claim that structured short-term risk assessment can improve clinical decision-making and can result in timely de-escalation actions, thus avoiding intrusive coercive interventions such as seclusion, restraint and forced administration of medication. ${ }^{13-18}$ As far as we know, the first randomised trial of short-term risk assessment in acute psychiatric wards was conducted by Abderhalden et al. ${ }^{19}$ In this Swiss study, nurses on the experimental acute admission wards used the Brøset Violence Checklist (BVC) as a violence risk assessment tool during the first 4 days of admission. ${ }^{20}$ The result of this intervention was a decrease in the number of incidents of severe aggression and the use of coercive medication. ${ }^{19}$

Our study is an extension of that by Abderhalden et al. ${ }^{19}$ In contrast to their study, we performed daily risk assessments during the entire admission period. In addition to the BVC, other instruments for symptom evaluation and danger to self or others were used. Our primary aim was to investigate the effects of short-term risk assessment on the number of aggression incidents and the use of seclusion, which is still a highly prevalent intervention in The Netherlands to manage aggressive and disruptive behaviour in psychiatric settings. ${ }^{1}$ We predicted reductions of both aggression incidents and seclusion rates as an effect of the intervention.

\section{Method}

A cluster randomised controlled trial was conducted over 40 weeks on four acute psychiatric wards. Four wards were divided into two experimental and control ward clusters (Fig. 1). These wards (36 beds in total: 20 beds on the experimental wards and 16 beds on the control wards) were located in an urban catchment area covering 900000 inhabitants of the Dutch city of Rotterdam and its suburbs. In all participating wards a similar selective admission policy was used. All patients admitted during the study period ( $n=597)$ were included in the trial. The average length of stay in the wards was approximately 3 weeks, mostly involuntarily $(62 \%)$. Most patients were diagnosed with a psychotic disorder $(58 \%)$.

\section{Intervention}

Patients were monitored daily by psychiatric nurses on the experimental wards by means of risk assessment scales, from the first day of admission until discharge or transfer to another ward. The item scores on the Crisis Monitor (see Appendix) were discussed during inter- and multidisciplinary meetings. On a daily basis the Brøset Violence Checklist and the Kennedy-Axis V (short version) scale were used to identify risks of loss of control that might result in imminent (but preventable) escalations on the ward. $^{20,21}$ Once a week the Kennedy-Axis V (full version), the Brief Psychiatric Rating Scale (BPRS), the Dangerousness Scale and the Social Dysfunction and Aggression Scale were used. ${ }^{21-25}$ These scales were used to evaluate mental state changes and current patient behaviour on a weekly basis. These five complementary scales covered a broad variety of common risk factors in acute psychiatric wards.

The Crisis Monitor was used for early recognition of patterns associated with (evolving) escalation and symptom (severity) 


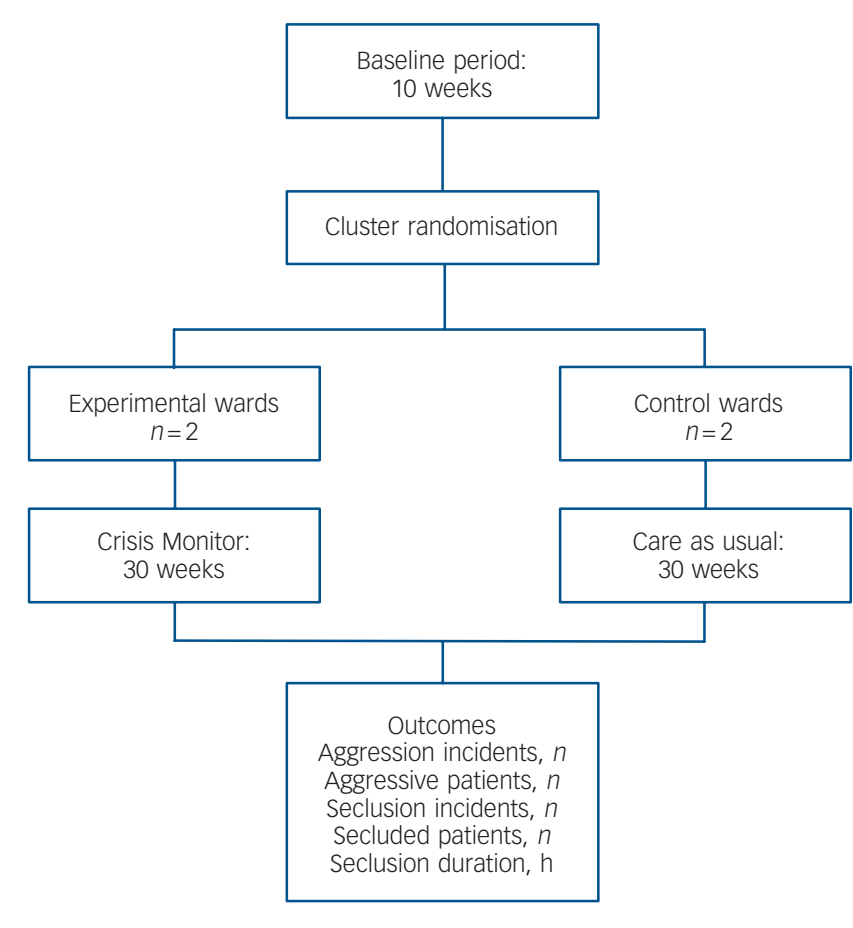

Fig. 1 Research design.

changes. All psychiatric nurses and doctors on the two experimental wards were trained to use the instruments on site directly after the random allocation of the wards to either the experimental or the control cluster. The Crisis Monitor ratings were discussed by the multidisciplinary team on a daily basis and in more detail in the weekly treatment planning meetings. Administration of the daily Crisis Monitor took approximately $5 \mathrm{~min}$ and weekly ratings took about $15 \mathrm{~min}$ for each patient. The structured risk assessment training as well as the ongoing clinical supervision were provided by a clinical nurse specialist supported by a risk assessment expert panel. Apart from focusing on more structured observations, the scales were fully incorporated into short-term clinical decisionmaking, intervention planning and evaluation. The Crisis Monitor scores guided more focused discussions on how to deal with observed changes in risks, such as timely verbal de-escalation, behavioural limit-setting, close observation and reintegration to the ward after seclusion.

\section{Treatment as usual}

On the two control wards treatment as usual was provided. This meant unstructured psychiatric observations and treatment based on clinical judgement. In other words, on the control wards no risk assessment tool was used whatsoever. Prior to the trial, teams on all four wards were trained in the registration of aggression and seclusion incidents as they occurred. This was important for outcome measurement. As was the case on the experimental ward, the clinical nurse specialists monitored adequate registration of these incidents on a daily basis.

\section{Procedures}

As with the study by Abderhalden et al, ${ }^{19}$ all wards recorded aggression incidents by means of the Staff Observation Aggression Scale - Revised (SOAS-R). ${ }^{26}$ This scale covers the following aspects of aggression incidents: the apparent trigger, the type and target of the aggression, consequences of the incident, and the interventions used by the staff to deal with the aggressive behaviour. Each aggression incident was reported, and the location, date and time of the incident were also recorded.

Seclusion episodes were recorded using the Argus scale, ${ }^{1,27}$ which enables detailed collection and analysis of seclusion rates, in terms of both incidence and duration of the seclusion. On the Argus scale a seclusion incident is defined as a sequence of periods of seclusion separated by no more than $24 \mathrm{~h}$; for example, two single hours in seclusion separated by $36 \mathrm{~h}$ would be counted as two seclusion incidents, whereas two single hours in seclusion separated by less than $24 \mathrm{~h}$ would be counted as one seclusion incident. According to Dutch law all such incidents must be reported to the Dutch Mental Health Inspectorate. The reliability of Argus assessments has been tested by means of comparison of nurses' ratings with other documentary information such as nurses' and doctors' notes, team meeting notes and letters to the Mental Health Inspectorate, and has proved to be fair to good (Cohen $\kappa=0.64-0.92)$. In all sources registration errors may occur. Hospitals with electronic medical charts showed better Cohen $\kappa$ values than hospitals using paper charts or paper and pencil registration. ${ }^{1}$

At the end of the 10-week baseline period the wards were randomly allocated to either the experimental or the control condition for the 30-week intervention period. In the two experimental wards, the risk assessment scales (Crisis Monitor) were introduced as part of care planning. The regional ethics committee approved the protocol.

The procedures were continuously monitored by a clinical nurse specialist to avoid underreporting of aggression incidents and seclusion use in both experimental and control arms. The nurse specialist visited the wards twice a day during the morning and afternoon team meetings. Such data control and management in clinical research follows recommendations in other studies. ${ }^{28-30}$ A low threshold and neutral availability of an external clinical nurse specialist may enhance the quality of data collection and also support clinicians by means of a non-blaming critical companionship approach. ${ }^{31}$

\section{Statistical analysis}

Differences in patient characteristics during the baseline and intervention periods were tested by chi-squared and $t$-tests. Potential differences between the experimental and the control wards during baseline and intervention phases in the number of aggression incidents and seclusion incident rates as well as time spent in seclusion were analysed by calculating the incidence rate per 1000 hospitalisation days. Differences in the duration of seclusion incidents between the experimental and control wards were analysed by comparing the total number of hours spent in seclusion with the total number of admission hours on the wards within the observation period. From these raw incidence rates we calculated the risk ratios for an event for each of the control and experimental clusters. Finally, the relative risk reduction (RRR) was reported. ${ }^{32}$ Analyses were performed using Predictive Analytics statistical software version 17.0 for Windows.

To determine whether risk ratios were affected by coincidental differences in patient characteristics on all wards, regression analyses were performed for baseline and intervention periods separately. A logistic regression analysis was performed with patient characteristics and diagnosis as predictors and seclusion as the dependent variable. A Poisson regression analysis on the rate of seclusion incidents per admission days was undertaken to investigate any intervention effect on the number of seclusion incidents, controlling for patient characteristics. A Poisson regression was also undertaken on the number of hours spent in seclusion. In both Poisson regression analyses the logarithm of the duration of admission was included as offset, to correct for 
admission time at patient level. The significance level for all statistical tests was set at $P<0.05$, two-tailed.

\section{Results}

In the 40-week study period, 617 admissions of 597 individual patients occurred on the four wards. During the 10-week preintervention period 170 patients were resident on the wards. During the intervention period 458 patients were resident on the wards, of whom 207 were admitted to an experimental ward and 251 to a control ward. Thirty-one patients were admitted in both periods. Patient characteristics during the baseline and intervention periods are presented in Table 1, together with baseline incident counts.

During the baseline period patient characteristics on the wards randomised to the experimental and the control clusters did not differ significantly with respect to age and gender (Table 1). Patients on the experimental wards, however, were more often from an ethnic minority background, more often involuntarily admitted and more likely to be diagnosed with a psychotic or a personality disorder. The total time spent in seclusion was longer on the experimental wards than on the control wards. Neither the number of aggression or seclusion incidents, nor the number of aggressive or secluded patients, differed significantly between clusters. During the intervention period the sample characteristics compilation remained constant, with more patients being involuntarily admitted as well as more patients with psychotic disorder being treated on the experimental wards. However, the numbers of patients from ethnic minorities were similar between the experimental and control wards during the intervention period (Table 1).

\section{Aggression}

The number of incidents of aggression decreased on the experimental wards from baseline to intervention period compared with the control wards. Relative risk ratios between the baseline and intervention period changed substantially, revealing a lower risk of aggression incidents on the experimental wards (Table 2; RRR $=-68 \%$; risk ratio at baseline $1.12,95 \% \mathrm{CI}$ $0.72-1.76$, at intervention $0.36,95 \%$ CI $0.26-0.50)$. When converted into number of aggression incidents per week, the rate on the experimental wards decreased from 4.9 incidents per week (i.e. 49 incidents over 10 weeks) during the baseline period to 1.7 incidents per week (52 incidents over 30 weeks) during the intervention period. On the control wards, the number of aggression incidents hardly changed, going from 3.5 incidents per week (35 incidents over 10 weeks) during baseline to 3.9 incidents per week (117 incidents over 30 weeks) during the intervention period. Otherwise, the number of patients engaged in aggression showed a (non-significant) trend towards reduction on the experimental wards during the intervention period (Table 2) compared with the control wards. The relative risk ratios of the number of aggressive patients between the experimental and the control wards, corrected for the number of patient days, however, did show a clear decrease $(-50 \%)$ between the baseline (risk ratio $\mathrm{RR}=1.13,95 \% \quad \mathrm{CI} \quad 0.57-3.10)$ and intervention period $(\mathrm{RR}=0.62,95 \% \mathrm{CI} 0.40-0.99)$, albeit with a $13 \%$ overlapping confidence interval $(P<0.10)$.

\section{Seclusion}

The number of hours spent in seclusion decreased significantly on the experimental wards after the introduction of the Crisis Monitor, in comparison with the control wards (Table 2). A significant decrease of $-45 \%$ in the risk ratio was observed in seclusion hours per admission hours, showing no overlapping confidence intervals: baseline period $\mathrm{RR}=1.12$ (95\% CI 1.011.19), intervention period $\mathrm{RR}=0.62$ (95\% CI $0.58-0.66)$. The number of seclusion incidents showed a small but not significant decrease $(-15 \%)$ from baseline $(\mathrm{RR}=1.19,95 \% \mathrm{CI} 0.76-1.88)$ to

\begin{tabular}{|c|c|c|c|c|}
\hline & Experimental wards & Control wards & Statistical comparison & $P$ \\
\hline \multicolumn{5}{|l|}{ Baseline period (10 weeks) } \\
\hline Number of patients, $n$ & 80 & 90 & & \\
\hline \multicolumn{5}{|l|}{ Patient characteristics } \\
\hline Age, years: mean (s.d.) & $38(13)$ & $40(11)$ & $t(168)=0.974$ & 0.33 \\
\hline Gender, male: $n(\%)$ & $53(66)$ & $54(60)$ & $\chi^{2}(1)=0.712$ & 0.40 \\
\hline Ethnic minority, $n(\%)$ & $31(39)$ & $16(18)$ & $\chi^{2}(1)=9.312$ & 0.002 \\
\hline Involuntarily admitted, n (\%) & $70(88)$ & $39(43)$ & $\chi^{2}(1)=35.900$ & 0.001 \\
\hline \multicolumn{5}{|l|}{ Diagnosis, $n$ (\%) } \\
\hline Psychotic disorder & $59(74)$ & $51(57)$ & $\chi^{2}(1)=5.400$ & 0.02 \\
\hline Personality disorder & $20(25)$ & $5(6)$ & $\chi^{2}(1)=7.122$ & 0.006 \\
\hline Drug misuse first diagnosis & $3(4)$ & $3(3)$ & $\chi^{2}(1)=0.916$ & 0.537 \\
\hline \multicolumn{5}{|l|}{ Ward characteristics } \\
\hline Number of beds & 20 & 16 & & \\
\hline Aggression incidents at baseline & 49 & 35 & $\chi^{2}(1)=0.249$ & 0.61 \\
\hline Aggressive patients, $n$ & 13 & 11 & $\chi^{2}(1)=0.426$ & 0.51 \\
\hline Seclusion incidents at baseline & 49 & 33 & $\chi^{2}(1)=0.565$ & 0.45 \\
\hline Secluded patients, $n$ & 28 & 20 & $\chi^{2}(1)=1.903$ & 0.16 \\
\hline Total number of seclusion hours & 1382 & 985 & $\chi^{2}(1)=7.395$ & 0.001 \\
\hline \multicolumn{5}{|l|}{ Intervention period (30 weeks) } \\
\hline Number of patients, $n$ & 207 & 251 & & \\
\hline \multicolumn{5}{|l|}{ Patient characteristics } \\
\hline Age, years: mean (s.d.) & 38.0 & 39.4 & $t(427)=1.092$ & 0.28 \\
\hline Gender, male: $n(\%)$ & $135(65)$ & $138(55)$ & $\chi^{2}(1)=4.572$ & 0.033 \\
\hline Ethnic minority, $n$ (\%) & 71 (34) & 77 (31) & $\chi^{2}(1)=0.683$ & 0.409 \\
\hline Involuntarily admitted, $n$ (\%) & $180(87)$ & $110(44)$ & $\chi^{2}(1)=92.310$ & 0.001 \\
\hline \multicolumn{5}{|l|}{ Diagnosis, $n(\%)$} \\
\hline Psychotic disorder & $137(66)$ & $122(49)$ & $\chi^{2}(1)=14.272$ & 0.001 \\
\hline Personality disorder & $59(28)$ & $21(8)$ & $\chi^{2}(1)=11.774$ & $<0.0001$ \\
\hline Drug misuse first diagnosis & $18(9)$ & $8(3)$ & $\chi^{2}(1)=1.972$ & 0.114 \\
\hline
\end{tabular}


Table 2 Aggression and seclusion rates during the baseline period (10 weeks) and intervention period (30 weeks)

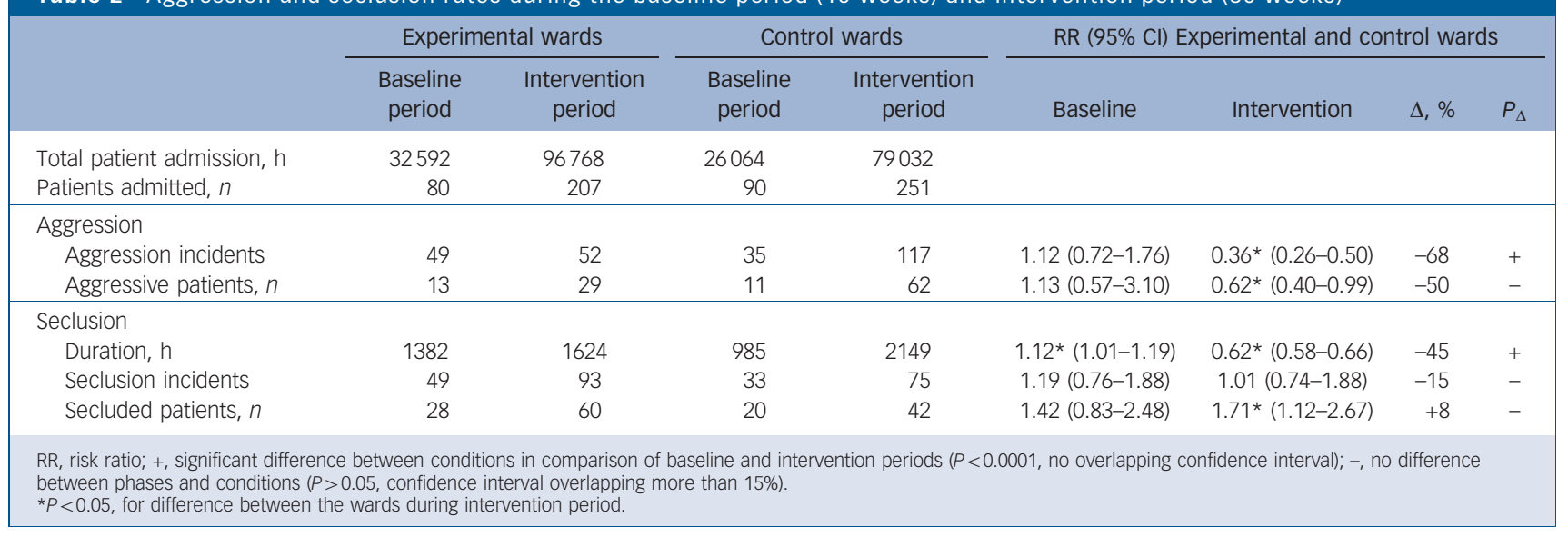

intervention $(\mathrm{RR}=1.01,95 \% \mathrm{CI} 0.74-1.88)$. The number of individual patients exposed to seclusion also did not increase significantly ( $+8 \% ; 100 \%$ overlapping confidence intervals) on the experimental wards during the intervention period, despite a relatively significant increase in the number of patients secluded in the control ward (RR at baseline 1.42, 95\% CI 0.83-2.48; RR at intervention $1.71,95 \%$ CI $1.12-2.67$ ), but again with $100 \%$ overlapping confidence intervals.

Regression analyses controlling for patient characteristics on time spent in seclusion per number of admission days revealed significant intervention effects but in opposite directions for baseline $(\beta=-0.71, P=0.005)$ and intervention periods $(\beta=1.34$, $P<0.0001$; goodness-of-fit statistics: deviance 479.419 , d.f. $=131$ and deviance 1596.856 , d.f. $=419$, respectively). In this model both short-term $(\beta=-0.78, P<0.0001)$ and long-term $(\beta=-2.25$, $P<0.0001)$ involuntary admission and psychotic disorder $(\beta=-1.71, P<0.0001)$ showed a negative association with time spent in seclusion. Being aged less than 35 years also showed a positive association with time spent in seclusion $(\beta=0.35$, $P=0.005$ ). Various other regression analyses performed on seclusion incidents and number of secluded patients showed no effect of the intervention, but again involuntary admission as well as a psychotic disorder predicted these outcome variables. Therefore, it seems fair to conclude from these regression analyses that observed differences in patient characteristics did not explain the reduction of time spent in seclusion found on the experimental wards after implementation of the Crisis Monitor.

\section{Discussion}

Our study suggests that a structured short-term risk assessment incorporated into routine care planning led to significant reductions in the number of aggression incidents and reliance on seclusion (expressed as the total time spent in seclusion). On the experimental wards seclusions in the intervention period occurred as frequently as on the control wards, but were far shorter in duration. In line with the findings of Abderhalden et $a l,{ }^{19}$ the reduction in aggression incidents as well the duration of seclusion on the experimental wards may be potentially explained by the fact that nurses identified indicators of imminent aggression - including increased agitation - at an earlier stage. Although our study is substantially smaller than that by Abderhalden et al, the number of aggression incidents and the number of hours spent in seclusion showed not only a statistically significant decrease, but also a risk reduction rate of over $50 \%$. It is possible that this new procedure fostered early team awareness not only of the increased risk of behavioural escalation, but also of a decreased risk after a patient has been secluded. Application of the Crisis Monitor may have stimulated more timely consideration in the multidisciplinary team of the justification for keeping patients in seclusion when risks started to decline. This suggests that patients benefit from the frequent use of short-term structured risk assessments on psychiatric admission wards. Without the use of structured risk assessments on a daily basis, it may take longer than necessary before ward staff become aware of improvement in the behaviour of secluded patients or act upon it. Nevertheless, despite these promising results, especially as far as the reduction of time spent in seclusion is concerned, the structured risk assessment approach did not result in fewer seclusion incidents. This suggests that seclusion could not be prevented in several instances, but it seems likely that the constant monitoring of the symptoms and risks was helpful in substantially reducing the length of time spent in seclusion.

\section{Limitations of the study}

A limitation of the study was that it took place on only four wards of a single hospital, and the total numbers of aggression and seclusion incidents observed (253 and 250 respectively) were low. As a result of the small number of participating wards, differences in patient characteristics at baseline between the experimental and control wards could not be prevented. However, using Poisson and logistic regression analysis we controlled for differences in patient characteristics. Even though randomisation was not completely successful, the effect of the intervention on duration of seclusion was significant, controlled for observed differences in patient characteristics by means of regression analyses. It is important that our findings are replicated in other studies using similar wards and risk assessments.

Another limitation of our study was that the participating staff could not be kept unaware of the condition they were participating in, and thus expectancy phenomena may have played a part in the decisions the teams made. It may be that the use of seclusion declined because staff members on the experimental wards expected that escalation risks would be reduced by the application of the Crisis Monitor, which enabled staff to focus more on positive risk management strategies. A third limitation related to this is that nurses who had to rate the outcome measures of aggression incidents and seclusion interventions also performed the Crisis Monitor ratings. This may have led to rater bias. An inherent problem of this kind of study is that the nurses who have to perform the risk assessments are the same nurses who provide seclusion room care, and in our study were also the nurses 
documenting aggression incidents. In future studies this latter bias could be addressed by having independent raters present around the clock, although this might be difficult to achieve in clinical practice.

Finally, a limitation of performing a cluster randomised trial in a single hospital was the risk of carry-over effects caused by nurses on the experimental wards informing nurses on the control wards about the intervention. However, because working with the Crisis Monitor requires specific training and changes in the structure of ward meetings, this effect may have been small, but may have partly limited the effects of the intervention. Thus, any carry-over effect would have reduced the effects of the Crisis Monitor.

\section{Strengths of the study}

In line with the study by Abderhalden et al, ${ }^{19}$ we demonstrated that a randomised clinical trial is feasible, even in the hectic working environment of an acute psychiatric ward. In the Swiss study structured risk assessment was used only during the first 4 days of the admission, whereas in our study all patients were monitored during the entire admission period: not only was aggression rated but so also were psychiatric symptoms by means of the Kennedy-Axis V and the BPRS. These broader ratings influenced input in clinical supervision as well as team treatment meetings. This comprehensive approach was developed to change the focus of the team from solely dealing with aggressive behaviour when it occurred, to a more continuous monitoring of patient functioning, as well as dealing with symptoms before behavioural problems became manifest.

All nurses collected data and no patient had to be excluded from the study. The extra time needed for obtaining the risk assessment scores appeared to be compensated for by the reductions in time required for extensive multidisciplinary discussions about patients' psychiatric condition and for the intensive care of patients when in seclusion. After the study period all teams decided to continue to work with the Crisis Monitor and also recommended this approach to other acute psychiatric wards.

\section{Clinical and practical implications}

Working with this structured risk assessment approach on these psychiatric admission wards resulted in less aggression and a reduction of time spent in seclusion by patients. It did not lead to extra costs in staffing apart from availability of a clinical supervisor. Nurses with advanced training and clinical leadership competencies could possibly also fulfil the role of clinical supervisor. Regular process evaluations and team feedback on risk identification and advanced critical thinking about the necessity for coercive interventions would improve the level of decisionmaking on psychiatric admission wards. Data generated from risk assessment scores might improve individualised treatment plans as well as ward policy-making in general.

R. van de Sande, MSC, Mental Health Centre Bavo-Europoort, Rotterdam, and Hogeschool Utrecht, University of Applied Science, Utrecht; H. L. I. Nijman, PhD, Radboud University Nijmegen, Behavioural Science Institute, Nijmegen;

E. O. Noorthoorn, PhD, GGnet Dutch Case Register on Containment Measures, Warnsveld; A. I. Wierdsma, PhD, Erasmus Medical Centre (MC), Department of Warnsveld; A. I. Wierdsma, PhD, Erasmus Medical Centre (MC), Department
Psychiatry, Research Centre O3, Rotterdam; E. Hellendoorn, Clinical Nurse Specialist, Mental Health Centre Bavo-Europoort, Rotterdam; C. van der Staak, PhD, Hogeschool Utrecht, University of Applied Science, Utrecht; C. L. Mulder, PhD, Mental Health Centre Bavo-Europoort, and Erasmus MC, Department of Psychiatry, Research Centre 03, Rotterdam, The Netherlands

Correspondence: R. van de Sande, Mental Health Centre Bavo-Europoort, Rotterdam, The Netherlands. Email: r.vandesande@parnassiabavogroep.nl

First received 4 Apr 2011, final revision 18 Jul 2011, accepted 28 Jul 2011

\section{Funding}

The study was funded by the Dutch Ministry of Health to investigate interventions that might contribute to the reduction of use of seclusion in The Netherlands.

\section{Appendix}

\section{Crisis Monitor}

\section{Instruments for daily application}

Kennedy Axis $V$ (short version) ${ }^{21}$

Level of patient strengths and risks in functioning on the first four items of the Kennedy Axis V, covering:

(a) psychological impairment

(b) social skills

(c) violence

(d) activities of daily living - occupational skills.

Broset Violence Checklist ${ }^{20}$

Presence or absence of behaviour that is predictive of violent incidents, such as confusion, irritability, boisterousness, verbal threats, physical threats, attacks on objects.

\section{Instruments for weekly application}

Kennedy Axis V (full version) ${ }^{21}$

The first eight subscales, covering:

(a) psychological impairment

(b) social skills

(c) violence

(d) activities of daily living - occupational skills

(e) substance abuse

(f) medical impairment

(g) ancillary impairment

(h) motivation.

\section{Brief Psychiatric Rating Scale 22,23}

Covering content and severity of 26 psychiatric symptoms over four dimensions: thought disturbances, anergia, affect and disorganisation.

\section{Dangerousness Scale 24}

Dangerousness levels on eight items, including self-neglect, self-harm, social breakdown, violence towards others or being victimised by others.

Social Dysfunction and Aggression Scale ${ }^{25}$

An 11-item scale containing 11 non-directed and directed behavioural problems varying from aggression towards self to outward aggression.

\section{References}

1 Janssen W, Noorthoorn EO, de Vries W, Hutschenmaekers GJM, Nijman HLI, Smit A, et al. Separaties in psychiatrische ziekenhuizen 2002-2008: Nederland internationaal vergeleken. Maanblad Geestelijke Volksgezondheid [Seclusions in psychiatric hospitals 2002-2008: The Netherlands internationally compared. Dutch Mental Health Care Monthly] 2009; 64: 457-69.

2 Nijman H, Palmstierna T, Almvik R, Stolker J. Fifteen years of research with the Staff Observation Aggression Scale; a review. Acta Psychiatr Scand 2005; 111: $12-21$.

3 Finke LM. The use of seclusion is not evidence-based practice. I Child Adolesc Psychiatr Nurs 2001; 4: 186-90.

4 Lendemeijer B, Shortrigde-Bagget L. The use of seclusion in psychiatry: a literature review. Sch Inq Nurs Pract 1997; 11: 299-315.

5 Veltkamp E, Nijman H, Stolker JJ, Frigge K, Dries P, Bower L. Patients' preferences for seclusion or forced medication in acute psychiatric emergency in the Netherlands. Psychiatr Serv 2008; 59: 209-11. 
6 Frueh BC, Knapp RG, Cusack KJ. Patients' reports of traumatic or harmful experiences within the psychiatric setting. Psychiatr Serv 2005; 56: 1123-32.

7 Soorgaard KW. Patients' perception of coercion in acute psychiatric wards: an intervention study. Nord J Psychiatry 2004; 58: 4-8.

8 Hoekstra T, Lendemeijer HHGM, Jansen MGMJ. Seclusion: the inside story. J Psychiatr Ment Health Nurs 2004; 11: 276-83.

9 Moran A, Cocoman A, Scott P, Matthews A, Staniuliene V, Valimaki M. Restraint and seclusion: a distressing treatment option? J Psychiatr Ment Health Nurs 2009; 16: 599-605.

10 Sailas $\mathrm{E}$, Fenton $\mathrm{M}$. Seclusion and restraint for people with serious mental illness. Cochrane Database Syst Rev 2000; 2: CD001163.

11 Gaskin CJ, Elsom SJ, Happell B. Interventions for reducing the use of seclusion in psychiatric facilities. Br J Psychiatry 2007; 191: 298-303.

12 Bowers L, Van Der Merwe M, Nijman H, Hamilton B, Noorthoorn EO, Steward $D$, et al. The practice of seclusion and time out on English acute psychiatric wards, the City-128 study. Arch Psychiatr Nurs 2010; 24: 275-86.

13 Linaker OM, Busch-Iversen $\mathrm{H}$. Predictors of imminent violence in psychiatric inpatients. Acta Psychiatr Scand 1995; 92: 250-4.

14 O'Rourke M, Hammond S. Risk Assessment, Management and Audit System: Towards Safe, Sound and Supportive Service. Surrey Hampshire Borders NHS Trust, 2000.

15 Crowe M, Carlyle D. Deconstructing risk assessment and management in mental health nursing. J Adv Nurs 2003; 43: 19-27.

16 Gale TM, Hawley CJ, Sivakumaran T. Do mental health professionals really understand probability? Implications for risk assessment and evidence based practice. J Ment Health 2003; 12: 417-30.

17 Secker J, Benson A, Balfe E, Lipsedge M, Robinson S, Walker J. Understanding the social context of violent and aggressive incidents on an inpatient psychiatric unit. J Psychiatr Ment Health Nurs 2004; 11: 172-8.

18 Hawley C, Littlechild B, Sivakumaran T, Sender H, Gale T, Wilson K. Structure and content of risk assessment proformas in mental health care. J Ment Health 2006; 15: 437-48.

19 Abderhalden C, Needham I, Dassen T, Halfens R, Haug HJ, Fisher JE. Structured risk assessment and violence in acute psychiatric wards: randomised controlled trial. Br J Psychiatry 2008; 193: 44-50.
20 Almvik R, Woods P, Rasmussen K. The Brøset Violence Checklist; sensitivity, specificity and interrater reliability. J Interpers Violence 2000; 15: 1284-96.

21 Kennedy JA. Mastering the Kennedy Axis V: A New Psychiatric Assessment of Patient Functioning. American Psychiatric Publishing, 2003.

22 Overall JE, Gorham DR. The Brief Psychiatric Rating Scale (BPRS): recent developments in ascertainment and scaling. Pharmacopsychiatry 1988; 24 97-9.

23 Dingemans $P$, Linszen $D$, Lenoir $M$, Smeets R. Component structure at the expanded Brief Psychiatric Rating Scale. Psychopharmacology 1995; 122 : 263-7.

24 Baars van A, De Schaal voor Gevaar. In De Epidemie van Dwangtoepassingen in de Psychiatrie (eds CL Mulder, A Snijdewind). Mension, 2006.

25 Wistedt B, Rasmussen A, Pedersen L, Malm U, Traskman-Bendz L, Wakelin J, et al. The development of an observer-scale for measuring social dysfunction and aggression. Pharmacopsychiatry 1990; 23: 249-52.

26 Nijman $H$, Muris $P$, Merckelbach $H$, Palmstierna $T$, Wistedt B, Vos B, et al. The Staff Observation Aggression Scale Revised (SOAS-R). Aggress Behav 1999; 3: 197-209.

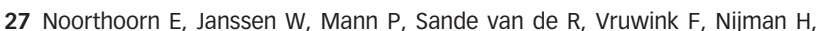
et al. Twee Jaar Argus, Rapportage Voorlopige Uitkomsten Metingen Vrijheidsbeperkende Maatregelen. Project Verslag Landelijk Project Dwang en Drang GGZ Nederland, 2008.

28 Owen C, Tarantello C, Jones M. Violence and aggression in psychiatric units. Psychiatr Serv 1998; 49: 1452-7.

29 De Niet G, Hutschemaekers G, Lendemeijer HHGM. Is the reduction effect of the Staff Observation Aggression Scale owing to a learning effect? An explorative study. J Psychiatr Ment Health Nurs 2005; 12: 687-94.

30 Tenneij N, Didden R, Stolker J, Koot H. Markers for aggression in inpatient treatment facilities for adults with mild to borderline intellectual disability. Res Dev Disabil 2009; 30: 6.

31 Titchen A, McGinley M. Facilitating practitioners' research through critical companionship. Nurs Times Res 2003; 8: 115-31.

32 Smithson M. Confidence Intervals. Quantitative Applications in the Social Sciences Series 140. Sage, 2003.

There is horror in carers turning into killers. Hospitals readily provide the means and opportunity. Doctors in the Japanese Imperial Army Biological Warfare Unit 731 killed experimentally, and in Nazi Germany to end Lebensunwertes Leben. Elsewhere motive is a puzzle. Beverley Allitt killed young children by injection or suffocation: Munchausen syndrome by proxy, perhaps, though murder with no intermediary. Benjamin Geen in Banbury engineered cardio-respiratory arrest in patients whom he might heroically resuscitate, if they were lucky. Colin Norris killed old ladies by injecting insulin, ostensibly because he disliked old ladies. Bad, not mad, maybe - but certainly dangerous to know. 